\title{
COVID-19: Estado, sociedad (industrial) del riesgo y gestión de las amenazas y carencias del 6 de marzo al 30 de abril del 2020 en Costa Rica
}

Recibido: 9 de febrero de 2021 Revisado: 13 de agosto de 2021 Aprobado: 16 de septiembre de 2021

\section{Stuart Daniel Chavarría Chinchilla Costarricense. Estudiante de licenciatura de la carrera de Ciencias Políticas. Asistente de investigación en la Cátedra Humboldt, el Centro de Investigación y Estudios Políticos (CIEP) y en el Observatorio de la Política Nacional (OPNA), Costa \\ ORCID: 0000 0003 1173 6390 Correo electrónico: stuartch1998@hotmail.com}

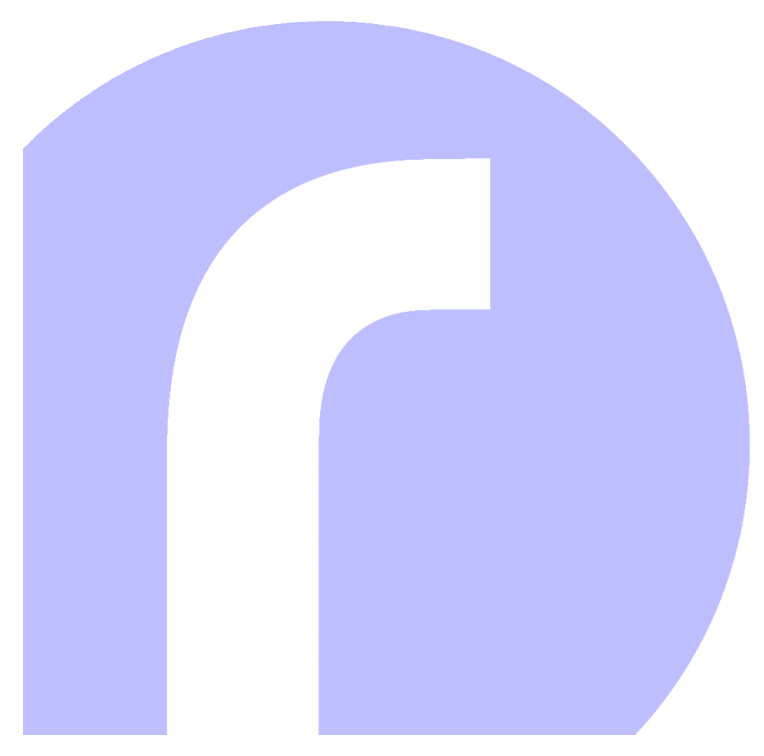

https://revistas.uned.ac.cr/index.php/rupturas

(c) (i) (3) (-)
Resumen: El presente artículo es un estudio de caso interpretativo que intenta evaluar la teoría de la sociedad del riesgo a partir de la gestión estatal de la pandemia por COVID-19. Para esto, se enfoca en Costa Rica como unidad de análisis en tanto se busca probar que, a diferencia de lo que apunta la teoría, la carencia material y el nivel de desarrollo, por sí solos, no explican el crecimiento y prosperidad de los riesgos. En cambio, para el presente trabajo se argumenta que, si se busca entender tanto el crecimiento como la prosperidad de los riesgos, es necesario examinar cuáles son las acciones estatales para gestionar dichos riesgos.

Palabras clave: COVID-19, riesgo planetario, pandemia, mortalidad, sociedad del riesgo

\section{COVID-19: State, Society (Industrial) of risk and management of threats and lacks from March 6 to April 30, 2020 in Costa Rica}

\begin{abstract}
This article is an interpretive case study that attempts to evaluate the theory of risk society based on the state management of the COVID-19 pandemic. For this, it focuses on Costa Rica as a unit of analysis as it seeks to prove that, contrary to what the theory points out, material deficiencies and the level of development alone do not explain the growth and prosperity of risks. On the other hand, for the present work it is argued that if one seeks to understand both the growth and the prosperity of risks, it is necessary to examine what are the state actions to manage said risks.
\end{abstract}

Key words: COVID-19, planetary risk, pandemic, mortality, Risk Society 


\section{Introducción}

En la presente investigación, se identifica cómo las medidas estatales y la influencia de ciertos actores, en la implementación de una estrategia sanitaria, condicionan el rol del Estado, en un período que comprende del 6 de marzo al 30 de abril de 2020 en Costa Rica. Postulamos, a la luz de la teoría de la sociedad del riesgo, que se debería considerar el papel del Estado como variable para explicar el crecimiento o no de los riesgos. Observamos cómo la función que adopte el Estado en crisis coyunturales está mediado por el conjunto de medidas que componen una estrategia de gestión sanitaria, por la influencia de las élites en la implementación de dicha estrategia y por los arreglos y capacidades de los regímenes de bienestar.

La importancia de estudiar el rol del Estado en la implementación de una estrategia de gestión de la crisis sanitaria se debe a que es el ente encargado de gestionar el solapamiento de diversos conflictos (económicos, sanitarios, políticos, sociales, entre otros) en el marco de crisis coyunturales, las cuales generan escenarios similares a estados de excepción. El rol que asume el Estado tiene efectos directos en el crecimiento de los riesgos propios de la modernidad avanzada.

La teoría seleccionada, a pesar de que inicialmente se planteó a la luz de los riesgos ecológicos, ha demostrado su capacidad de generalización tras una serie de crisis biológicas, económicas, nucleares y políticas de finales del siglo XX y principios del siglo XXI (Reyna 2018, 97) y en la actualidad se puede relacionar con la pandemia de COVID-19 (Domínguez 2020, 42). La sociedad del riesgo supone un cambio en las dinámicas sociales, políticas y económicas y el surgimiento de nuevos fenómenos, que muchos marcos analíticos no pueden analizar. En este sentido, el carácter proyectivo de la teoría es un punto a favor, ya que nos permite tener un sólido marco teóricoexplicativo (Beck 1998, 15-18; Sales 2009, 18-19; Reyna 2018, 102) para un fenómeno y realidades tan nuevas, como la pandemia por COVID-19.

Sin embargo, la teoría cae en el sesgo de dividir el planeta en países industriales del primer mundo con mejores capacidades de respuesta ante estos nuevos riesgos y países del tercer mundo, donde crecen más los riesgos producto de la carencia material, débiles seguridades sociales y bajo crecimiento económico.

La investigación busca evaluar y refutar la teoría, a la luz del caso costarricense y observando las estrategias de gestión de la crisis sanitaria, en el marco del COVID-19, ya que este caso nos permite demostrar el cambio que se ha producido en el sur global, donde existen Estados con fuertes regímenes de política sociales y que tienen la capacidad de contener los riesgos asociados, en este caso, al COVID-19. Esto nos permite refutar el uso de categorías analíticas, como el primer y tercer mundo, pues están unidas a con- 
cepciones jerárquicas, erróneas, eurocéntricas y sesgadas sobre las capacidades humanas, institucionales y económicas del sur global, y, por lo tanto, se pueden identificar como dispositivos de control del patrón moderno-colonial.

En síntesis, postulamos que la carencia material y el nivel de desarrollo no permiten comprender el crecimiento de los riesgos. En su lugar, se debería observar el rol del Estado y su capacidad para implementar una estrategia de gestión sanitaria. El primero resulta importante para comprender el crecimiento de los riesgos, pues su incremento se puede ver frenado por el éxito de una estrategia de gestión sanitaria. Sin embargo, el punto clave es que el éxito en la implementación de una estrategia está mediada por el conjunto de medidas que finalmente se aplique, por la influencia de las élites en la definición de la estrategia y por las capacidades y arreglos de un régimen de bienestar.

\section{Metodología}

Para la propuesta metodológica, partiremos de la base epistemológica del racionalismo aplicado de Bachelard (1973), según el cual los diferentes actos epistemológicos de la práctica científica no pueden separarse entre sí. Por lo tanto, aspectos como la recolección de datos empíricos, la construcción del caso, el valor de la teoría para romper con el sentido común y generar una ruptura epistemológica tienen el mismo valor e importancia para la investigación. En este sentido, para llegar a los hechos científicos, el investigador debe primero conquistar, formular y observar la realidad social (Venneson 2013, 242-243). A partir de esta base epistemológica, formulamos la estrategia metodológica que sigue la investigación (tabla1).

La metodología seleccionada es el análisis de caso, ya que es una estrategia de investigación empírica de uno o varios fenómenos con el propósito de analizar la configuración de cada caso en particular y, a partir de ahí, aclarar fenómenos mayores. De esta manera, se permite evaluar o refutar una teoría. La investigación, al ser un estudio de caso interpretativo, utiliza marcos teóricos para dar explicaciones sobre casos especiales. Este tipo de estudios de caso permiten también dar lugar a procesos de evaluación y mejora de teorías (Venesson 2013, 240-242).

En este sentido, dicha metodología permite emplear y evaluar la teoría de la sociedad del riesgo, a la luz de un caso en particular como el costarricense, dando la posibilidad de comprender fenómenos mayores relacionados al rol en general de los Estados en la gestión de riesgos y amenazas, o permite también comprender las condiciones en que se da el crecimiento o no de los riesgos en la modernidad avanzada. Por lo tanto, Costa Rica se convierte en "La unidad de análisis es el qué o quién que está siendo explorado. Es decir, es donde se enfoca la mirada (...) con el fin de recolectar información y responder a las preguntas planteadas» (BID 2011, 4). 
1. Se define esta fecha pues, a partir de mayo, podemos ver un cambio en la estrategia de gestión de la crisis sanitaria (BCCR 2020, 7).

\begin{tabular}{|c|c|c|}
\hline \multicolumn{3}{|c|}{$\begin{array}{l}\text { Tabla 1. Estructura metodológica: } \\
\text { actos epistemológicos del proceso investigativo }\end{array}$} \\
\hline Selección del caso & Marco teórico & Observación empírica \\
\hline Definición & Definición & Definición \\
\hline $\begin{array}{l}\text { Según Bachelard (1973), } \\
\text { los casos son el primer } \\
\text { acto epistemológico que } \\
\text { busca la ruptura con la } \\
\text { sabiduría convencional. } \\
\text { El investigador es quien } \\
\text { construye, delimita, define } \\
\text { y describe el caso, así } \\
\text { como elabora categorías } \\
\text { basadas en los resultados } \\
\text { de su estudio, o bien } \\
\text { mediante categorías } \\
\text { convencionales, ya sean } \\
\text { estas legales, políticas o } \\
\text { económicas. }\end{array}$ & $\begin{array}{l}\text { Según Bachelard (1973), } \\
\text { la investigación en el } \\
\text { estudio de caso implica } \\
\text { utilizar la teoría para } \\
\text { transformar los datos, en } \\
\text { todo un nuevo } \\
\text { vocabulario analítico } \\
\text { apropiado, que puede ser } \\
\text { empleado en otros casos. } \\
\text { El investigador revisa sus } \\
\text { principales conceptos a la } \\
\text { luz del estudio de caso, } \\
\text { porque justamente se } \\
\text { halla aprendiendo de } \\
\text { este. }\end{array}$ & $\begin{array}{l}\text { Según Bachelard (1973), } \\
\text { el tercer acto } \\
\text { epistemológico es la } \\
\text { observación empírica. } \\
\text { Toda investigación } \\
\text { necesita amarrar las } \\
\text { intenciones teóricas con } \\
\text { un análisis empírico de la } \\
\text { realidad. Para esto, el } \\
\text { investigador puede utilizar } \\
\text { distintos métodos, y } \\
\text { combinar datos } \\
\text { cuantitativos y } \\
\text { cualitativos. }\end{array}$ \\
\hline Descripción & Descripción & Descripción \\
\hline $\begin{array}{l}\text { El rol del Estado en la } \\
\text { implementación de una } \\
\text { estrategia de gestión } \\
\text { sanitaria frente a la crisis } \\
\text { desarrollada por el } \\
\text { COVID-19, en Costa } \\
\text { Rica, del } 1 \text { de marzo del } \\
2020 \text { al } 30 \text { de abril del } \\
2020 \text {. }\end{array}$ & $\begin{array}{l}\text { El marco teórico utilizado } \\
\text { y que buscamos refutar } \\
\text { es la teoría de la } \\
\text { sociedad del riesgo de } \\
\text { Uldrich Beck. }\end{array}$ & $\begin{array}{l}\text { Los métodos o técnicas } \\
\text { que emplearemos en la } \\
\text { investigación son: } \\
\begin{aligned} \text { 1. Análisis } \\
\text { documental } \\
\text { 2. Estudio de caso } \\
\text { 3. Análisis de datos } \\
\text { cualitativos y } \\
\text { cuantitativos }\end{aligned}\end{array}$ \\
\hline
\end{tabular}

Elaboración propia a partir de Venneson, P. (2013).

El periodo de análisis se concentra en la primera etapa de la pandemia por COVID-19, que va desde que se registra el primer contagio el 6 de marzo hasta el 30 de abril en Costa Rica ${ }^{1}$. Dicho periodo resulta notable para refutar la teoría, puesto que, durante los primeros meses de la pandemia, el virus no creció; lo que contradice los postulados de la teoría.

De hecho, gracias al caso costarricense, observamos que la cercanía entre las élites políticas y económicas ocasionó que las políticas de gobierno se anticiparan a las demandas empresariales (Cárdenas, Martínez y Robles 2020, 13-14). Esto facilitó que, al inicio de la segunda etapa (junio-agosto), las élites influenciaran una flexibilización de la estrategia sanitaria que terminó ocasionando un alza en los contagios (OPNAb 2020, 4-5; BCCR 2020, 7; 
OPNAa 2020, 30) y demostró el peso que tiene el rol del Estado en el crecimiento o prosperidad de los riesgos.

Se debe hacer la anotación metodológica de que los resultados aquí expuestos son parte de un proceso más amplio de investigación, que se enmarca como parte del trabajo final de graduación para obtener el grado de Licenciatura en Ciencias Políticas. A continuación, exponemos los resultados originales en dos apartados principales:

1. Una discusión teórica sobre la relación entre la sociedad industrial del riesgo y el COVID-19.

2. Una discusión empírica sobre el rol del Estado en el marco coyuntural producido por el COVID-19 y las medidas implementadas en la gestión de la crisis sanitaria.

En el primer apartado, la discusión se construye a partir del análisis de diversas fuentes documentales y usa datos cuantitativos como las muertes acumuladas, los contagios acumulados y la tasa de mortalidad, permitiendo demostrar la relación entre la sociedad industrial del riesgo y el COVID-19 como un riesgo imperceptible y autoamenazante, que nace del conocimiento científico y el avance de la producción. En el segundo apartado, la discusión se realiza a partir del análisis de fuentes documentales, que sirven de contextualización y nos permiten ver las afectaciones y los conflictos que tuvo que gestionar el Estado en el marco coyuntural creado por el COVID-19. Este segundo apartado se fortalece con el análisis de la base de datos del Observatorio de la Política Nacional (2020) "Medidas gubernamentales para aliviar la situación COVID-19", la cual nos permite monitorear, de manera general, las medidas estatales y la estrategia gubernamental que implementó el Estado en el periodo seleccionado para así dilucidar qué instituciones activo y cómo se perfiló el rol del Estado en esta primera etapa.

En resumen, para determinar el rol del Estado en este contexto, donde debió gestionar problemas y conflictos muy variados, se torna fundamental analizar las medidas estatales, la fortaleza de su régimen de bienestar y la presión que pudieron ejercer las élites en la definición de una estrategia de gestión sanitaria y el rol que adoptó el Estado. Sin embargo, para este avance de resultados, presentamos solo un análisis de las medidas que ejecutó el Estado en el periodo de análisis.

\section{Sociedad industrial del riesgo en el marco coyuntural del COVID-19}

La crisis del COVID-19 ha cambiado por completo las condiciones de vida en la Tierra. En este contexto, el Estado tuvo que asumir la función de resguardar la salud pública y ejecutar medidas inéditas, que restringen la movilidad de las personas; creando un ambiente cuasi revolucionario, donde el estado de excepción se convirtió en el estado de normalidad (Agamben 2020, 18; Beck 1998, 87; Coto 2020, 3; Nancy 2020, 30; OPNA 2020, 4). 
Esto nos lleva a argumentar que el virus se puede entender como un riesgo imperceptible y autoamenazante, propio de la modernidad avanzada, donde la producción social de la riqueza va acompañada de la producción social del riesgo. Por lo tanto, los problemas y conflictos asociados a la sociedad de la carencia son sustituidos por los problemas y conflictos que surgen de la producción, definición y reparto de los riesgos producidos de manera científicotécnica. Este cambio en la matriz de los conflictos y problemas en la modernidad avanzada se vincula con dos condiciones históricas: 1. este cambio se consuma allí donde el nivel alcanzado por las fuerzas productivas, humanas y tecnológicas, así como por las seguridades y regulaciones de un Estado social, permitieron reducir la miseria, y 2. este cambio depende de que mientras crecen las fuerzas productivas en la modernidad avanzada, también se liberan riesgos y autoamenazas en un nivel sin precedentes (Beck 1995, 25).

\begin{tabular}{|c|c|}
\hline \multicolumn{2}{|c|}{ Dos paradigmas de sociedad } \\
\hline $\begin{array}{c}\text { Objetivo en la } \\
\text { sociedad industrial clásica }\end{array}$ & $\begin{array}{c}\text { Objetivo en la } \\
\text { sociedad (industrial) del riesgo }\end{array}$ \\
\hline $\begin{array}{l}\text { En la sociedad industrial o de clases, los } \\
\text { problemas y conflictos giraban en torno a } \\
\text { cómo repartir la riqueza de una manera } \\
\text { desigual y aun así socialmente legítima. }\end{array}$ & $\begin{array}{l}\text { En la sociedad del riesgo, el objetivo es } \\
\text { cómo minimizar, evitar y canalizar riesgos } \\
\text { ocasionados por el proceso avanzado de } \\
\text { modernización, y cómo limitarlos, repartirlos } \\
\text { y justificarlos como efectos secundarios } \\
\text { latentes, que no obstaculicen el avance del } \\
\text { proceso avanzado de modernidad, ni } \\
\text { sobrepase el límite de lo soportable. }\end{array}$ \\
\hline \multicolumn{2}{|c|}{ Principal cambio } \\
\hline \multicolumn{2}{|c|}{$\begin{array}{l}\text { En esta transición de un esquema a otro, las cuestiones de la aplicación y desarrollo de } \\
\text { tecnologías son sustituidas por la gestión política y científica de los riesgos de la aplicación } \\
\text { de ciertas tecnologías, o son reemplazados por la gestión de los riesgos liberados producto } \\
\text { del crecimiento de los sistemas productivos industriales. El progreso de la modernización se } \\
\text { vuelve reflexivo. }\end{array}$} \\
\hline Primer mundo & Tercer mundo \\
\hline $\begin{array}{l}\text { Se pierden de vista el reparto y los conflictos } \\
\text { de la riqueza. La lucha por la carencia } \\
\text { material y el pan de cada día pierden } \\
\text { urgencia. }\end{array}$ & $\begin{array}{l}\text { El reparto y los conflictos de la riqueza se } \\
\text { encuentran en primer plano. }\end{array}$ \\
\hline $\begin{array}{l}\text { Esto ocasiona que se pierda una lucha } \\
\text { política central, que deja a las demás en las } \\
\text { sombras. En lugar del hambre, aparecen } \\
\text { problemas relacionados con la obesidad y la } \\
\text { nueva pobreza. }\end{array}$ & $\begin{array}{l}\text { El pensamiento y la actuación de los seres } \\
\text { humanos están dominados por la evidencia } \\
\text { de la carencia material, por la "dictadura de } \\
\text { la miseria". }\end{array}$ \\
\hline
\end{tabular}

Elaboración propia a partir de Beck, U. (1998). 
Esta transformación de la matriz de los conflictos, ocasionado por el surgimiento de nuevos riesgos imperceptibles, ha provocado un cambio por completo en las dinámicas sociales creando dos marcos distintos de sociedad. En este sentido, podemos ver que, en la sociedad industrial del riesgo, a pesar de que los riesgos sean el eje central del conflicto (como es en el caso del COVID-19), aun así, los problemas relacionados a la carencia material no desaparecen del todo y más bien se pueden ver amplificados por el estado de excepción creado. En la tabla 2 se presenta una explicación de ambos paradigmas.

Esta visión teórica que nos aporta la tabla 2, por un lado, nos permite observar que la lucha contra la carencia material, por la que se está dispuesto a aceptar riesgos o "efectos secundarios adversos" es la base de legitimación en la que se asienta el proyecto de la modernidad avanzada (Beck 1998, 26). Además, nos permite observar cómo la producción social de riesgos autoimperceptibles y autoamenazantes, nacidos producto del conocimiento técnicocientífico y del desarrollo de las fuerzas productivas, termina creando todo un nuevo paradigma de sociedad, donde la gestión y el reparto de dichos riesgos toma un papel central en la política.

De hecho, si se observa el marco coyuntural creado por el COVID-19 en Costa Rica, es posible atestiguar cómo los conflictos asociados a la definición y reparto de los riesgos ocasionados por el COVID-19 fueron la tónica que condicionó los conflictos en otros ámbitos de la sociedad, ya que, producto del virus y las medidas para impedir su crecimiento en el territorio, inevitablemente, se afectó la economía, el crecimiento económico, aumentó el desempleo, se perjudicó seriamente el mercado laboral y los ingresos de los hogares cayeron; se recalca cómo los conflictos típicos de la sociedad de la carencia se amplifican y solapan con el surgimiento de los conflictos asociados a los riesgos.

Aunque la gestión de riesgos autoamenazantes e imperceptibles han transformado por completo a las sociedades contemporáneas y las dinámicas políticas. Los problemas de la sociedad de la carencia no han desaparecido del todo. De hecho, según Beck (1998), aún en la sociedad industrial del riesgo se puede observar un fenómeno que denominamos la paradoja del solapamiento de la carencia y los riesgos, la cual nos habla sobre cómo se solapan en la modernidad avanzada las situaciones y conflictos sociales de una sociedad «repartidora de riqueza» con las de una sociedad «repartidora de riesgos».

La cuestión es que Beck posee una visión sumamente eurocéntrica de los países del sur global y argumenta que, en términos del reparto de los riesgos: la ignorancia de los riesgos no perceptibles encuentra su justificación en lugares como el tercer mundo, donde la supresión de la miseria palpable es el terreno cultural y político donde florecen, crecen y prosperan los riesgos y las amenazas. Por lo tanto, en la sociedad del riesgo vence la lógica de la producción de riqueza y precisamente por ello al final vence la lógica de los riesgos (Beck 1998, 40-41, 51). 
2. Los datos son de las primeras nueve semanas desde que se registró el primer contagio.
La paradoja descrita es un recurso teórico sumamente importante porque permite observar cómo, en el marco de una crisis como la del COVID-19, los conflictos y problemas asociados al riesgo se solapan con los conflictos y problemas relacionados a la carencia material. En este sentido, el rol del Estado en el marco coyuntural del COVID-19 se tuvo que concentrar en gestionar la tensión entre la salud pública y la económica, pues las medidas para enfrentar el virus afectaron directamente el ámbito económico, amplificando problemas relacionados a la carencia material, que el Estado debió atender mediante medidas estatales y la coordinación interinstitucional.

Sin embargo, la teoría posee un notable sesgo al dividir al planeta en dos grandes categorías, tales como 1) países del primer mundo industrializados, que han suprimido la miseria palpable, con las seguridades de Estados de bienestar sólidos, que los preparan mejor ante los riesgos, y 2) países del tercer mundo donde la supresión de la miseria palpable, tal y como apunta la teoría, se convierte en el terreno cultural y político donde florecen, crecen y prosperan los riesgos y las amenazas. En contraste con lo apuntado por la teoría, en el marco coyuntural del COVID-19 más bien podemos observar en la tabla 3 cómo, al inicio de esta pandemia, los países más afectados fueron del primer mundo y si los comparamos con países centroamericanos, parece ser que los riesgos crecieron y prosperaron más en los primeros, contradiciendo por completo a la teoría.

\begin{tabular}{|c|c|c|c|c|}
\hline \multicolumn{5}{|c|}{$\begin{array}{l}\text { Tabla 3. Comparación entre países } \\
\text { en el marco coyuntural del COVID-19 }\end{array}$} \\
\hline País & Periodo $^{2}$ & $\begin{array}{l}\text { Número total de } \\
\text { contagios }\end{array}$ & $\begin{array}{l}\text { Número total } \\
\text { de muertes }\end{array}$ & $\begin{array}{l}\text { Tasa de } \\
\text { letalidad }\end{array}$ \\
\hline $\begin{array}{l}\text { Estados } \\
\text { Unidos }\end{array}$ & $\begin{array}{l}22 \text { enero-24 } \\
\text { marzo. }\end{array}$ & 56,698 & 1,004 & $1,8 \%$ \\
\hline Italia & $\begin{array}{l}31 \text { enero-2 } \\
\text { abril. }\end{array}$ & 115,242 & 13,915 & $12,1 \%$ \\
\hline España & $\begin{array}{l}1 \text { febrero-3 } \\
\text { abril. }\end{array}$ & 119,199 & 11,198 & $9,4 \%$ \\
\hline Costa Rica & $\begin{array}{l}6 \text { marzo-7 } \\
\text { mayo. }\end{array}$ & 716 & 6 & $0,9 \%$ \\
\hline El Salvador & $\begin{array}{l}19 \text { marzo-14 } \\
\text { mayo. }\end{array}$ & 1112 & 23 & $2,7 \%$ \\
\hline Guatemala & $\begin{array}{l}14 \text { marzo-9 } \\
\text { mayo. }\end{array}$ & 967 & 24 & $2,48 \%$ \\
\hline
\end{tabular}

Elaboración propia a partir de datos de Hassel, J., Ortiz-Ospina, E., Ritchie, H. y Roser, M. (2020). 
Como se puede ver, la teoría de Uldrich Beck aporta un marco teórico-conceptual apto para entender el surgimiento y las implicaciones sociales de este tipo de riesgos en las dinámicas políticas y sociales, que surgen tras la transición a una sociedad del riesgo. Sin embargo, aun así, hay ciertos aspectos que apunta la teoría que resultan contradictorios con la realidad.

Por ejemplo, la sobrevaloración que le adjudica a la carencia material y al nivel del desarrollo económico resultan excesivos. Esto por cuanto se observa cómo, en el marco coyuntural que crea el COVID-19, estas variables y la división del planeta en el primer y el tercer mundo, al menos durante los primeros meses de la pandemia, no tuvieron tanto peso para explicar el crecimiento y prosperidad de los riesgos. Por lo que se ve claramente cómo, entre los países más afectados, se encontraron países históricamente asociados al primer mundo occidental, como Estados Unidos (Butler 2020, 60) o Italia que al inicio de la pandemia registró cientos de muertes diarias y fue el brote que despertó las alarmas en Occidente. (Harvey 2020, 86; Han 2020, 98). De hecho, al inicio, la pandemia actual golpeó en gran escala al mundo occidental (Badiou 2020, 68), mientras "al parecer Asia tiene mejor controlada la pandemia que Europa” (Han 2020, 97; Harvey 2020, 88).

Por lo tanto, vemos que el uso de categorías como primer y tercer mundo es una herramienta de control del patrón moderno-colonial (Bello 2015, 48-49), que busca construir una jerarquía desde una visión eurocéntrica, donde Europa es la medida universal y el estadio final de la modernidad y la humanidad (Quijano 2014, 789; Bello 2015, 46; Durán 2018, 105). Su uso reproduce jerarquías que colocan a los países del norte global como exitosos, desarrollados y poderosos, en contraposición con los perdedores, subdesarrollados y débiles países del sur global.

La expresión "tercer mundo" es el primer dispositivo ideológico que encarna la lógica moderna-colonial de otrificación en el contexto de fin del colonialismo. Desde la invención del desarrollo, se define su contenido remitiendo a la pobreza —entiéndase incapacidad de producir riqueza-, a la ignorancia entiéndase incapacidad para generar conocimiento-, al tradicionalismo entiéndase atraso-, etc. (Bello 2015, 50).

Esto demuestra que las categorías de primer y tercer mundo poseen sesgos altísimos. Si bien es cierto la carencia material y el nivel de desarrollo son variables por considerar a la hora de analizar el crecimiento de los riesgos en la modernidad avanzada, su uso puede llevar a conclusiones sesgadas sobre el reparto de los riesgos en el planeta, y reproduce la idea de que el norte global es superior, la medida universal de las cosas, que se hallan en un estadio de la modernidad sumamente avanzado, y que, por lo tanto, los riesgos de la modernidad avanzada no los afectarán, de igual manera, como a los subdesarrollados y débiles países del sur global.

Se postula que, en lugar de basar el análisis del crecimiento de los riesgos en las variables propuestas por el autor $y$, a partir de la división entre primer y ${ }^{3}$ caracterización errónea del sur tercer mundo ${ }^{3}$, resulta más apropiado observar la consolidación de regíme- global. 
nes de bienestar y su influencia en la capacidad y el papel del Estado para hacer frente a crisis coyunturales como la ocasionada por el COVID-19. Puesto que muchas de las problemáticas, que surgieron producto de la atención de la crisis sanitaria, su atención pasa por la política social y por sectores de esta como la salud, educación, seguridad social, entre otros (Minteguiaga y Ubasart-González 2016, 215). El universalismo adquiere una mayor relevancia en el marco del COVID-19, debido a que este debilita las jerarquías y crea un estándar de valor para toda la población (Martínez y Sánchez-Ancochea 2019, 44), lo cual es sumamente necesario, dado que los riesgos del virus afectan de maneras distintas y desiguales al género, las razas y las clases. (Domínguez 2020, 43-44). Por cuanto el objetivo de la política social al ser alcanzar el bienestar y la atención de necesidades tanto material como inmaterial, en áreas como la salud, la educación o incluso el prestigio social (Franco 1984,61). Alcanzar el bienestar y suplir el surgimiento de necesidades de índole sanitarias, educativas o vinculadas al ingreso económico es de primera importancia en el marco de una pandemia, donde se solapan conflictos sumamente diversos.

Dicho esto, resulta importante hacer una revisión sobre la literatura de regímenes de bienestar que nos permita caracterizar las capacidades del Estado de bienestar en el sur global. En general, un primer inconveniente es que en los primeros trabajos asociados a regímenes del bienestar tenían, al igual que la teoría de Beck, un sesgo eurocéntrico. Puesto que se analizaron modelos del norte global, a partir de los casos de Estados Unidos, los países escandinavos y Alemania, lo cual llevó a la formulación de tres grandes regímenes de bienestar: el liberal, el socialdemócrata o el corporativo (Esping-Andersen 1990, 47-19).

El problema con estos primeros trabajos era que las categorías elaboradas fueron pensadas solo para analizar países desarrollados, dentro del análisis estaban ausentes la variable de género, el papel de los cuidados y el rol de la familia (Minteguiaga y Ubasart-González 2016, 213, 217-218). De hecho, el primer enfoque dominante basó el universalismo, a partir del caso de los países escandinavos en lugar de realizar una evaluación más general de los resultados alcanzados por estas y otras latitudes. Por ende, las políticas sociales universales se definieron, a partir de la experiencia histórica de Suecia y sus países vecinos, como programas financiados por impuestos generales a los que toda la población tenía acceso como asunto de derecho y con base al principio de ciudadanía (Martínez y Sánchez-Ancochea, 6, 39, 54, 67-68; Esping-Andersen 1990, 38).

Siempre se argumentó que se debía replicar el modelo socialdemócrata en otras latitudes, a pesar de que su implementación exacta era sumamente complicada de alcanzar, en especial dentro de una realidad como la latinoamericana. En dicha región, la gran desigualdad en los ingresos, la concentración del poder político en una pequeña élite, la débil capacidad fiscal, la debilidad de la clase trabajadora y la sociedad civil, la incapacidad del mercado de ser un agente incorporador, la inestabilidad política y la volatilidad macroe- 
conómica se pensaba que obstaculizaban la creación y expansión de programas dirigidos a toda la ciudadanía y financiados mediante impuestos generales (Filgueira 1998, 3-4; Martínez y Sánchez-Ancochea 2019, 6). Por mucho tiempo, esto llevó a creer a los investigadores que el sur global, por su atraso económico y una serie de condiciones sociales y políticas, era incapaz de formular políticas sociales sólidas, y, en términos del riesgo, era incapaz de controlar su crecimiento.

Sin embargo, lo cierto es que, a pesar de que en Latinoamérica no fuera posible replicar el modelo socialdemócrata, esto no quiere decir que la región no tenga casos donde haya sido capaz de instaurar sólidos regímenes de bienestar y acercarse a la universalidad. Así pues, los casos de Mauricio, Costa Rica, Corea del Sur o Uruguay demuestran la posibilidad de que los países del sur global alcancen similares objetivos, en términos de la igualdad de acceso a programas sociales, con suficiencia para todas las personas y mediante instrumentos alternativos, sobre todo medidas contributivas (Martínez y Sánchez-Ancochea 2019, 36).

El universalismo en la región ha sido capaz de tener una gran capacidad redistributiva en los programas que cubren a una mayoría de la población, ha permitido disminuir el estigma, mejorar el estatus social de los pobres y ha contribuido a mejorar el sentido de pertenencia a la comunidad. Las políticas sociales con resultados universales, en el sur global, lejos de representar un costo, generan un impacto positivo en el crecimiento económico y la competitividad. La política social compensa tanto los efectos negativos de ajustes económicos y choques externos ${ }^{4}$ como contribuye a la generación de activos competitivos, siendo Mauricio y Costa Rica los mejores ejemplos de esta si4. Choques externos como la recesión ocasionada por el tuación (Martínez y Sánchez-Ancochea 2019, 43-44, 46, 49).

Al analizar el sur global, se debe evitar evaluar los instrumentos de política de manera normativa. Nunca se deben considerar programas amplios, con un gran alcance y financiados por impuestos generales como el punto de referencia para evaluar el resto de los instrumentos disponibles de política. Existen diversidad de arquitecturas de políticas que alcanzaron la universalidad, y la arquitectura escandinava no necesariamente provee los resultados esperados per se, pues otros tipos de seguro social pueden desempeñarse igual o mejor (Martínez y Sánchez-Ancochea 2019, 54-59), lo cual nos permite desmitificar la creencia de que en el sur global no es posible tener un sólido Estado social.

En general, lejos de lo que apunta Beck, el sur global cuenta con casos donde se pueden observar arreglos y seguridades propias de un Estado benefactor. De hecho, las trayectorias de Costa Rica, Corea del Sur, Mauricio y Uruguay pueden considerarse como los mejores escenarios de Estados sociales y posibles candidatos para alcanzar políticas sociales universales en el sur global. En los cuatro países, las políticas sociales han generado altos niveles de desarrollo humano. Además, los casos de Costa Rica y Mauricio han sido representados como atípicos en sus respectivas regiones ${ }^{5}$, debido a ${ }_{\text {región es América Latina, y en }}$. En laso de costa Ria la la alta inversión en salud, educación y pensiones. Parece ser, además, que el el de Mauricio, África. 
crecimiento económico no tiene poder explicativo para comprender las trayectorias de las arquitecturas políticas, en dichos países (Martínez y Sánchez-Ancochea 2019, 16-17, 19,60) y tampoco lo tiene para comprender el crecimiento y prosperidad de los riesgos.

En realidad, por los objetivos de la política social y por la capacidad de regímenes sociales como el de Costa Rica, los arreglos y seguridades de un Estado social tienen un peso explicativo mayor para comprender el crecimiento o no de los riesgos, dado que, como se mencionó antes, muchas de las necesidades, incertidumbres y problemas que surgieron producto del solapamiento de los riesgos y la carencia fueron atendidos por sectores de la política social.

Específicamente, contrario a los supuestos de la teoría, el caso costarricense se ha señalado como uno de los primeros países latinoamericanos en instaurar sistemas de seguridad social (Ubasart-González 2016, 221; Filgueira $1998,13)$ y más recientemente ha sido considerado, por otros autores, como un Estado de bienestar universal e integrador en una clásica socialdemocracia, o como un Estado de bienestar socialdemócrata embrionario (Antía 2018, 203-204; Martínez y Sánchez-Ancochea 2019, 11).

«En Costa Rica, la seguridad social alcanzó una amplia cobertura y una baja segmentación, al tiempo que se generó una amplia expansión de los servicios de educación y salud a casi toda la población» (Antia 2018, 203-204). La arquitectura fundacional de Costa Rica es un caso excepcional, que permitió la posterior expansión prouniversalista. El seguro social unificado costarricense fue construido de abajo hacia arriba, con un financiamiento por contribuciones tripartitas y sin copagos (Martínez y Sánchez-Ancochea 2019, 11, 23, $59,60,71,85,88)$.

Por lo tanto, Costa Rica, al estar ubicado bajo el precepto que se cuestiona en el sur global, es un importante referente de políticas sociales y permite desmitificar las condiciones propuestas por Beck (1998). El caso costarricense presenta un sistema de políticas sociales unificado con resultados universales, que, por ejemplo, a pesar de tener un PIB per cápita tres veces menor que el de Corea del Sur, presenta mínimas diferencias en sus indicadores sociales, lo cual señala el importante papel que cumple la política social (Martínez y Sánchez-Ancochea 2019, 62), y recalca el valor que esta puede llegar a tener para atender la carencia material y enfrentar los riesgos que brotan del COVID-19.

La pertinencia de estudiar el caso costarricense se debe a que, a pesar de ser un país del sur global, tuvo una gestión de la pandemia moderada en el periodo de estudio. Por lo tanto, este caso nos lleva a cuestionar el supuesto del que parte la teoría seleccionada, pues observamos que la carencia material y el nivel de desarrollo no permiten comprender el crecimiento y prosperidad de los riesgos asociados al COVID-19. Estudiar a Costa Rica nos permite observar que, para comprender el crecimiento de los riesgos, se debe examinar el éxito de una estrategia de gestión sanitaria que depende, en buena 
parte, del papel que asuma el Estado frente a la crisis. Así pues, dicho rol está mediado por el conjunto de medidas que construyen una estrategia sanitaria, por las características de su régimen de bienestar y por la influencia que tengan las élites en la implementación de dicha estrategia.

En síntesis, el usar conceptos como tercer mundo para explicar el reparto de los riesgos ocasiona que el análisis parta de una posición eurocéntrica y sesgada, donde prima una lógica de jerarquización y prima una preconcepción que deslegitima los esfuerzos humanos, institucionales y económicos de los países del sur global. Estas categorías no reflejan el cambio global ocurrido, especialmente en épocas en que, desde hace años, se habla del surgimiento de Estados de bienestar en el sur global, de la solidez de nuevos Estados en viejas regiones de África y Asia, o se habla de la emergencia de considerables complejos industriales en Sudamérica o el sudeste asiático, donde el crecimiento en zonas como São Paulo o Yakarta (Martínez y Sánchez-Ancochea 2019, 16; Horowitz 1972, 16) fueron algunas de las grandes hazañas de la modernidad avanzada.

\subsection{COVID-19 como riesgo de la sociedad industrial del riesgo}

El COVID-19 puede interpretarse como uno de los riesgos imperceptibles y autodestructivos que surgen de la sobreproducción industrial y el conocimiento científico-técnico (Beck 1998, 25-26, 28). Pues su lugar de origen es un mercado ${ }^{6}$, donde se mercantiliza la naturaleza y se hacinan animales en ina- 6. Este tipo de mercados decuadas condiciones sanitarias (Badiou 2020, 71; Harvey 2020, 84; OMS beneficia a una gran cantidad 2020); recalcando que la pandemia es el resultado del paso del virus de ani- actividades que se realizan allí, males silvestres extraídos de hábitats en degradación hacia los humanos por lo que se ignora el hecho (zoonosis), lo cual refleja el impacto de las actividades humanas en el en- de que estos lugares son torno natural (Amaris 2020, 35).

\section{patógenos.}

Se cree que el SARS-CoV-2 es un caso de zoonosis, es decir, una infección producida a través del salto del patógeno del hospedador original a un hospedador intermedio, para luego, así, saltar a los humanos (Benavides et al. $2020,16)$. Con este caso, vemos como «actitudes humanas que afectan directamente a la naturaleza de forma descontrolada, como las que causan el comercio, la caza y el consumo de animales silvestres, la perturbación de los espacios naturales o la sobreexplotación ganadera, dañan la biodiversidad y su efecto protector, y a la larga favorecen el trasvase de patógenos» (Benavides et al. 2020, 17).

Sin embargo, lo que no previó la teoría es que, en este asunto, el riesgo no toma la forma de químicos, ni de toxinas que se mezclan con la base natural y que viajan en el aire, la tierra, el agua y los alimentos (Beck 1998, 13, 47), sino que, en el caso en cuestión, el riesgo es un poderoso y nuevo patógeno capaz de ocasionar serias complicaciones médicas para la salud de los humanos en la tierra.

El tránsito local entre especies de animales hasta el ser humano constituye el punto de origen de la pandemia, demostrando, por un lado, el alcance global del capitalismo, así como la presencia intensa y universal del Estado chino 
en el mercado mundial (Badiou 2020, 71-72) y, por otro lado, evidencia el impacto del avance productivo y la mercantilización de la naturaleza en la generación de riesgos.

De hecho, China se convierte en el punto de confluencia clave, porque el anudamiento de mercados autóctonos tradicionales y la forma moderna en que se da la difusión planetaria del virus producto del mercado mundial capitalista (Badiou 2020, 72) permiten ver la confluencia de las dinámicas y conflictos de la sociedad industrial del riesgo y la sociedad industrial clásica, donde actividades comerciales son justificadas por suprimir la carencia material, a pesar de acabar generando riesgos autoamenazantes.

En virtud de ello, se puede argumentar que la COVID-19 es el riesgo que nos permite refutar, readecuar y evaluar la teoría escrita hace más de treinta años, dado que, cuando fue escrita, Beck mencionaba que estábamos en una etapa de transición, que aún no estábamos del todo en una sociedad de la carencia, ni en una sociedad del riesgo (Beck 1998, 27). Sin embargo, creemos que después de treinta años, y a la luz de la pandemia por COVID19 , la transición ha culminado y nos hallamos ante un verdadero cambio en la modernidad (Domínguez 2020, 41), donde la transición hacia dinámicas de una sociedad del riesgo se ha completado. Esta afirmación adquiere mayor relevancia, especialmente cuando se toma en cuenta que, con anterioridad, otros dos virus de este mismo tipo habían saltado de animales a humanos. Por ejemplo, el SARS-1 que apareció en noviembre de 2002 en el sur de China y se extendió a 26 países, llegó a los 8098 casos confirmados y 774 muertos, mientras el MERS fue registrado en Arabia Saudita en abril de 2012, sin embargo, presentó bajo números de contagio (Wallace 2020). De hecho, el virus responsable de la pandemia en el 2020, el SARS-2 (Severe Acute Respiratory Syndrom 2) recibe su nombre después de la epidemia de SARS-1, que se desplegó en la primavera de 2003 (Badiou 2020, 68).

En síntesis, lo expuesto demuestra la relación entre este tipo de mercados, la destrucción de la naturaleza, el sistema productivo industrial y el surgimiento de riesgos, ahora bajo la figura de patógenos peligrosos. La COVID-19 se transformó en un riesgo planetario, lo cual lo hace ajustarse al nuevo esquema de la sociedad del riesgo, al ser imperceptible, universal y altamente amenazante para la vida en la Tierra (Beck 1998, 27-29).

Por lo tanto, con el marco coyuntural que creó la COVID-19, es posible argumentar que, como nunca, estamos experimentando las dinámicas y los conflictos propios de una sociedad del riesgo. En especial, considerando que el origen del SARS-CoV-2 (así como de otras pandemias por SARS o ébola) se relaciona con las consecuencias del sistema agroalimentario industrial, los efectos del cambio climático, entre otras nocivas actividades (Amaris 2020, 34) y considerando que, en el marco de la modernidad avanzada y la sociedad del riesgo, las pandemias virales no tienen nada de excepcional o inaudito. En realidad, desde la pandemia del SIDA, pasando por la gripe aviar, el ébola, el SARS-1, entre otras, sabemos que el mercado mundial, las zonas con débiles sistemas de salud y la falta de disciplina en la vacunación propi- 
cian serias epidemias. Incluso de antemano se sabía con certeza de que, después del SARS-1, MERS y H1N1, ocurriría un nuevo brote mortal (Badiou 2020, 67-68; Domínguez 2020, 42).

\section{Costa Rica: el papel del Estado en el marco coyuntural del COVID-19}

Como mencionamos, podemos estar viviendo, gracias a la pandemia por COVID-19, el fin de la transición de una sociedad industrial clásica a una sociedad industrial del riesgo. Esto debido al incremento de los conflictos relacionados al riesgo, los cuales se solapan con conflictos relacionados a la carencia material, típicos de la sociedad industrial clásica. En el caso costarricense, se observa el solapamiento de problemas relacionados a la carencia y el riesgo, por ejemplo: se puede identificar cómo el desempleo o la disminución de los ingresos de los hogares se solapan con los riesgos a la salud que representa el virus. Esto porque los riesgos se reparten siguiendo el esquema de clases, pero al revés. Mientras la riqueza se acumula arriba, los riesgos se acumulan abajo en las clases vulnerables. Por lo tanto, los riesgos parecen fortalecer la sociedad de clases (Beck 1998, 40-41) y, ante esta situación, el Estado debe gestionar, mediante la política social y otros instrumentos, la tensión entre la salud y la economía, la tensión entre la salud y la carencia material de los estratos más bajos de la población.

De hecho, el bajo crecimiento económico y la caída en la actividad económica que experimentó el país durante la pandemia no son problemas nuevos, sino que son parte de una serie de problemáticas que Costa Rica ha venido arrastrando por más de treinta años. Es decir, desde el giro en los años ochenta, el cual apostó por un cambio en el modelo de desarrollo y Estado, y el cual ha optado desde entonces por la apertura económica y la integración del país al mercado internacional vemos que una serie de indicadores se han deteriorado (OPNAb 2020, 4; OPNAa 2020, 25). Esta pandemia solo ha venido a demostrar "las injusticias estructurales de nuestros ordenamientos sociales. Hoy se notan doblemente las (...) consecuencias del empobrecimiento, de la desigualdad, del desempleo, de la informalidad laboral, del inequitativo acceso a la salud" (Pineda 2020,15).

En este sentido, al observar la dinámica de Costa Rica dentro del marco coyuntural del COVID-19, vemos que la mayoría de los problemas que el país ha arrastrado por años solo se han amplificado. En este contexto, la función del Estado se volvió fundamental para gestionar conflictos de diversa índole, pues el Estado costarricense tuvo que ejecutar una estrategia de gestión de la crisis sanitaria para enfrentar los riesgos a la salud pública que, al ser ejecutada, terminó afectando a la economía y por ende al mercado laboral (OPNAb 2020, 4; OPNAa 2020, 25). Por ejemplo, la afectación en la economía se puede constatar, a partir de marzo, producto de las medidas implementadas para resguardar la salud pública, mientras que ya para octubre del 2020 dimensionamos la afectación en la economía nacional, producto de la implementación de estas medidas al observar una contracción económica del 4,5 
$\%$; siendo la más severa desde que se realiza la medición en 1950 (BCCRa $2020,4)$. De hecho, desde el momento en que se detectó el primer caso de contagio hasta la fecha, la economía nacional ha transitado por un periodo de fuerte desaceleración del crecimiento del producto interno bruto y seguido por una considerable contracción económica (BCCR 2021, 3).

Por su parte, el mercado laboral sufrió una seria afectación producto de la pandemia y las restricciones que esta trajo consigo, como, por ejemplo: el aumento en el desempleo, una disminución en los ingresos de los trabajadores y serias dificultades para ingresar al mercado laboral (INECa 2020, 2526; INECb 2020, 35). Demostrando, así, cómo las medidas estatales al intentar gestionar los riesgos y amenazas del COVID-19 también generaron afectaciones en otros ámbitos de la sociedad, lo cual recalca el solapamiento de conflictos de la carencia y el riesgo. De esta manera, los riesgos parecen fortalecer la sociedad de clases, en el sentido de que los ricos (en ingreso, poder y educación) pueden comprarse la seguridad y la libertad frente a los riesgos, mientras los pobres se hallan vulnerables ante estos (Beck 1998, 41). De hecho, solo los ingresos por concepto de subsidios estatales, becas y transferencias aumentaron (INECb 2020, 36), lo cual demuestra las intenciones del Estado por gestionar la paradoja del solapamiento de la carencia y los riesgos, al presentar iniciativas típicas de la política social, como pueden ser el Bono proteger y otras transferencias monetarias, que buscaban aliviar los problemas materiales de las clases más vulnerables.

Es pertinente mencionar que la incidencia del COVID-19 en el territorio nacional amplificó una serie de problemas que arrastraba el país por décadas, con lo que queda confirmado el efecto búmeran de los riesgos, pues estos terminan afectando al mismo sistema capitalista que los produce (Beck 1998, 29, 43). De hecho, los riesgos del COVID-19 causaron serios efectos en otros ámbitos de la sociedad afectando directamente a la economía, por eso se confirma que (...) «todo lo que amenaza a la vida en esta Tierra amenaza también a los intereses de propiedad y comercialización de quienes viven de que la vida y los medios de vida se conviertan en mercancía» (Beck 1998, 45).

En resumen, desde un punto de vista teórico en el marco coyuntural que creó el COVID-19, el Estado tuvo que gestionar y aliviar la tensión entre la protección de la salud pública y la carencia material, que surgió producto de las medidas estatales para combatir los riesgos asociados al COVID-19. Esta situación refleja la profundización de los conflictos propios de la sociedad del riesgo, donde el efecto búmeran de los riesgos no tiene que plasmarse solo en la amenaza directa de la vida, sino también en medios delegados: el dinero, las propiedades, la legitimación. Este efecto no solo golpea individualmente a las clases empresariales o al sistema capitalista, sino que también tiene un efecto globalizador e igualitario (Beck 1998, 44); la propagación del virus no solo afecta la salud individual y pública, sino también el crecimiento económico, el mercado laboral y el ingreso de los hogares, resaltando cómo el efecto bú- 
meran y la paradoja del solapamiento de la carencia y los riesgos desempeñan un papel central en las dinámicas políticas de la sociedad del riesgo.

\section{Costa Rica contra el COVID-19}

En la pandemia por COVID-19 en Costa Rica, solo durante la primera etapa, se pudieron contener drásticamente los efectos adversos de la pandemia, por lo que resulta fundamental indagar en las medidas ejecutadas en dicho periodo. Puesto que, ante los resultados favorables de la primera etapa, el Estado comenzó en mayo a optar por el levantamiento gradual de las restricciones, antes de lo previsto por el mismo Banco Central. Esta apertura económica y cambio en la estrategia, vale la pena destacar, se dio por la presión de grupos económicos poderosos, que tenían una relación de colaboración-reclutamiento con las élites políticas (Cárdenas, Martínez y Robles 2020; BCCRb 2020, 7; OPNAa 2020, 30). Sin embargo, una segunda ola de infección en junio, más agresiva que la primera en términos de cantidad de casos positivos y hospitalizados, debilitó el avance gradual de la apertura económica (BCCR $2020,7)$. Coincidiendo con lo apuntado por Vargas $(2020,115)$, quien nos dice que si nos remitimos a los casos nuevos registrados semanalmente, podemos observar una tendencia creciente en el número de contagios acumulados que tiende a acelerarse a finales de mayo y alcanza un pico de más del $100 \%$ a principios de julio.

Por lo tanto, vemos cómo efectivamente el crecimiento y prosperidad de los riesgos asociados al COVID-19 fueron desencadenados por cambios impulsados por grupos económicos poderosos, que terminaron flexibilizando la estrategia estatal de gestión de la crisis sanitaria, en favor de la apertura económica. Los actores que priorizaron la prosperidad económica por sobre la salud pública fueron, principalmente, los sectores del pequeño y mediano empresariado, así como las cámaras empresariales y asociaciones del sector empresarial privado, las cuales se vieron afectadas por las restricciones sanitarias y comenzaron a clamar por una reapertura y reactivación económica (Barahona, Cordero y Sibaja 2020, 4, 13). Esta situación recalca el valor de estudiar las medidas implementadas antes del cambio en la estrategia de gestión, para profundizar en la relación entre el crecimiento y prosperidad de los riesgos y el papel del Estado.

Concentrándose en la primera etapa, el primer caso reportado de un contagio en Costa Rica tuvo lugar el día 6 de marzo del 2020. Ante esta situación, el Estado tomó una serie de medidas para combatir mejor los futuros efectos adversos de la pandemia. La primera de estas medidas fue la Declaración de Alerta Amarrilla N. ${ }^{\circ}$ 09-20 dictada por la Comisión Nacional de Emergencias (CNE), y posteriormente fortalecida con el Decreto Ejecutivo N. ${ }^{\circ} 42227-\mathrm{MP}-\mathrm{S}$, la cual declaró emergencia nacional en todo el territorio costarricense (OPNAc 2020).

Estas medidas iniciales permitieron la gestión de recursos por vía excepcional y una mejor coordinación de acciones interinstitucionales; facilitando la 
respuesta del Gobierno ante la crisis sanitaria que se avecinaba. Durante la primera etapa de la crisis, se observa que el Estado comenzó a implementar medidas de aislamiento y distanciamiento, preparó la infraestructura hospitalaria y comenzó la compra de insumos médicos. Por otro lado, el Estado tomó una serie de medidas de alivio fiscal, suspensión de moratorias y adecuación de créditos para ayudar a las familias costarricenses y al sector productivo, así como empresarial del país (OPNAc 2020). Estas medidas fueron apenas una fase de preparación que le dio un periodo de gracia al Estado costarricense para tomar algunas acciones con el propósito de impedir daños mayores en la economía y el bolsillo de los hogares costarricenses, mientras, simultáneamente, realizaba coordinaciones interinstitucionales y acciones conjuntas para evitar el aumento de contagios, fortalecer el sistema de salud y asegurar el cumplimiento de las medidas de distanciamiento y aislamiento social.

En este sentido, se destaca que el Poder Ejecutivo fue el que orquestó una serie de acciones interinstitucionales para evitar la propagación de la enfermedad. Estas acciones estuvieron, en su mayoría, encabezadas por el Poder Ejecutivo, comandado por el Ministerio de la Presidencia y el Ministerio de Salud. Estos dos ministerios tuvieron el mando del Gobierno y delimitaron la estrategia de gestión de la crisis sanitaria durante las primeras nueve semanas.

La estrategia de gestión de la crisis sanitaria implementada por el Gobierno costarricense planteó tres objetivos, los cuales fueron: disminuir la curva de contagios, lograr la recuperación económica y brindar mayor apoyo a la población (OPNAc 2020). En este sentido, cada una de las medidas gubernamentales emprendidas por el Gobierno se pueden agrupar en cinco categorías, según las metas que buscaban cumplir, las cuales son: 1) aplacar la curva, 2) rescate social, 3) readecuación financiera, 4) alivio financiero y donaciones, y 5) apoyo a sectores. En la tabla 4 se explican las diferentes categorías utilizadas y resume la estrategia que siguió este en el periodo delimitado.

El papel del Poder Ejecutivo ha sido preponderante. Esto lo podemos confirmar de la base de datos del Observatorio de la Política Nacional (2020) al observar que el Ministerio de la Presidencia se ha concentrado en ejecutar medidas como la suspensión de actividades de concentración masiva, la suspensión del aumento salarial a todo el sector público, así como ha anunciado la declaración del estado de emergencia nacional para facilitar la coordinación y el uso oportuno de recursos.

Por otro lado, vale la pena destacar que, contrario a lo que se ha apuntado desde el inicio de la crisis, el Estado ha ejecutado medidas para evitar efectos adversos en la economía. Por ejemplo, en su momento se ocupó de establecer moratorias a los pagos de las pymes, así como se encargó de generar una inyección de capital a través del Programa Alivio, que destinó alrededor de 5.6 millones de dólares para 200 micros, pequeñas y medianas empresas que se vieron afectadas por la crisis. Además, se ejecutaron medidas para apoyar a sectores como el sector cultural, cárnico y lechero, mientras, por su 
parte, los ministerios se convirtieron en una extensión de la Presidencia al ejecutar una serie de acciones que refuerzan las medidas emprendidas por ella.

\begin{tabular}{|c|c|c|c|c|c|}
\hline Objetivos & Descripción & $\begin{array}{l}\text { Total de } \\
\text { medidas }\end{array}$ & Metas & Descripción & $\begin{array}{l}\text { Total de } \\
\text { medidas }\end{array}$ \\
\hline \multirow[t]{2}{*}{$\begin{array}{l}\text { Disminuir la } \\
\text { curva }\end{array}$} & \multirow{2}{*}{$\begin{array}{l}\text { Aplicar medidas } \\
\text { de } \\
\text { distanciamiento } \\
\text { y aislamiento } \\
\text { social para } \\
\text { asegurar la } \\
\text { disminución de } \\
\text { la curva de } \\
\text { contagios, así } \\
\text { como } \\
\text { concentrarse en } \\
\text { redirigir } \\
\text { recursos y } \\
\text { recibir } \\
\text { donaciones } \\
\text { para mejorar la } \\
\text { atención } \\
\text { médica, de tal } \\
\text { manera que } \\
\text { sea capaz de } \\
\text { reducir la curva } \\
\text { de contagios. }\end{array}$} & \multirow[t]{2}{*}{$\begin{array}{l}\text { Se } \\
\text { ejecutaron } \\
\text { un total de } \\
72 \\
\text { medidas. }\end{array}$} & $\begin{array}{l}\text { Aplacar la } \\
\text { curva }\end{array}$ & $\begin{array}{l}\text { Las medidas } \\
\text { congregadas } \\
\text { en esta } \\
\text { categoría se } \\
\text { orientan a } \\
\text { aplicar medidas } \\
\text { de aislamiento } \\
\text { y } \\
\text { distanciamiento } \\
\text {. }\end{array}$ & $\begin{array}{l}\text { Se } \\
\text { ejecutaro } \\
\mathrm{n} \text { un total } \\
\text { de } 48 \\
\text { medidas. }\end{array}$ \\
\hline & & & $\begin{array}{l}\text { Alivio } \\
\text { financiero } \\
\text { y } \\
\text { donacione } \\
\text { s }\end{array}$ & $\begin{array}{l}\text { Las medidas } \\
\text { agrupadas en } \\
\text { esta categoría } \\
\text { se ocupan de } \\
\text { dotar del } \\
\text { presupuesto e } \\
\text { insumos } \\
\text { médicos para } \\
\text { cumplir con sus } \\
\text { labores de } \\
\text { atención de la } \\
\text { pandemia. Esto } \\
\text { lo logra gracias } \\
\text { a donaciones, } \\
\text { traslados de } \\
\text { superávits de } \\
\text { otras } \\
\text { instituciones y } \\
\text { créditos de } \\
\text { organismos } \\
\text { internacionales. }\end{array}$ & $\begin{array}{l}\text { Se } \\
\text { ejecutaro } \\
\mathrm{n} \text { un total } \\
\text { de } 24 \\
\text { medidas. }\end{array}$ \\
\hline $\begin{array}{l}\text { Ayuda a la } \\
\text { población }\end{array}$ & $\begin{array}{l}\text { Ejecutar } \\
\text { acciones para } \\
\text { asegurar el } \\
\text { bienestar de } \\
\text { aquella } \\
\text { población } \\
\text { vulnerable y } \\
\text { que se ha visto } \\
\text { más afectada } \\
\text { por los embates } \\
\text { de esta } \\
\text { pandemia. }\end{array}$ & NA & $\begin{array}{l}\text { Rescate } \\
\text { social }\end{array}$ & $\begin{array}{l}\text { Las medidas en } \\
\text { esta categoría } \\
\text { buscan } \\
\text { asegurar el } \\
\text { bienestar de la } \\
\text { población más } \\
\text { afectada por } \\
\text { esta crisis } \\
\text { sanitaria. }\end{array}$ & $\begin{array}{l}\text { Se } \\
\text { ejecutaro } \\
\mathrm{n} \text { un total } \\
\text { de } 19 \\
\text { medidas. }\end{array}$ \\
\hline
\end{tabular}




\begin{tabular}{|c|c|c|c|c|c|}
\hline $\begin{array}{l}\text { Recuperación } \\
\text { económica }\end{array}$ & $\begin{array}{l}\text { Establecer } \\
\text { algunas } \\
\text { medidas para } \\
\text { asegurar la } \\
\text { recuperación } \\
\text { económica de } \\
\text { sectores clave. }\end{array}$ & NA & $\begin{array}{l}\text { Apoyo a } \\
\text { sectores } \\
\text { económic } \\
\text { os }\end{array}$ & $\begin{array}{l}\text { Las medidas } \\
\text { agrupadas en } \\
\text { esta categoría } \\
\text { buscan } \\
\text { asegurar la } \\
\text { recuperación } \\
\text { económica, y el } \\
\text { apoyo a ciertos } \\
\text { sectores } \\
\text { económicos. }\end{array}$ & $\begin{array}{l}\text { Se } \\
\text { ejecutaro } \\
\mathrm{n} \text { un total } \\
\text { de } 16 \\
\text { medidas. }\end{array}$ \\
\hline \multirow[t]{2}{*}{$\begin{array}{l}\text { Readecuación } \\
\text { financiera }\end{array}$} & \multirow[t]{2}{*}{$\begin{array}{l}\text { Establecer } \\
\text { medidas para la } \\
\text { readecuación } \\
\text { de pagos, } \\
\text { deudas y } \\
\text { moratorias en } \\
\text { beneficio de la } \\
\text { ciudadanía y } \\
\text { los sectores } \\
\text { económicos. }\end{array}$} & \multirow[t]{2}{*}{$\begin{array}{l}\text { Se } \\
\text { ejecutaron } \\
\text { un total de } \\
18 \\
\text { medidas. }\end{array}$} & $\begin{array}{l}\text { Para la } \\
\text { ciudadaní } \\
\text { a }\end{array}$ & $\begin{array}{l}\text { Las medidas en } \\
\text { esta categoría } \\
\text { buscan la } \\
\text { readecuación } \\
\text { de deudas, } \\
\text { pagos y } \\
\text { moratorias en } \\
\text { beneficio de la } \\
\text { población. }\end{array}$ & $\begin{array}{l}\text { Se } \\
\text { ejecutaro } \\
\mathrm{n} \text { un total } \\
\text { de } 6 \\
\text { medidas. }\end{array}$ \\
\hline & & & $\begin{array}{l}\text { Para el } \\
\text { sector } \\
\text { económic } \\
\text { o }\end{array}$ & $\begin{array}{l}\text { Las medidas en } \\
\text { esta categoría } \\
\text { buscan la } \\
\text { readecuación } \\
\text { de deudas, } \\
\text { pagos y } \\
\text { moratorias en } \\
\text { beneficio de las } \\
\text { empresas. }\end{array}$ & $\begin{array}{l}\text { Se } \\
\text { ejecutaro } \\
\mathrm{n} \text { un total } \\
\text { de } 12 .\end{array}$ \\
\hline
\end{tabular}

Elaboración propia a partir de datos del OPNAC (2020).

En este sentido, diferentes ministerios ejecutaron políticas para establecer el teletrabajo (MTSS), suspender lecciones (MEP), extender la aplicación de protocolos de salud para asegurar el distanciamiento y aislamiento social (MS), prohibir las visitas a los centros penales y lograr establecer que las instituciones deberían operar con $20 \%$ del personal; en aras de asegurar el distanciamiento y el aislamiento y por ende impedir el crecimiento del virus (OPNA 2020).

Ahora bien, no solo el Poder Ejecutivo tuvo un papel importante en esta coyuntura, sino también el resto de la institucionalidad costarricense cumplió un papel relevante en este periodo por analizar. Con el propósito de aclarar cuáles entidades participaron en este proceso de coordinación institucional es que, a continuación, presentamos un cuadro que contiene un mapeo de instituciones estatales dividido por las metas que orientan la acción institucional: 


\begin{tabular}{|c|c|}
\hline Metas & Mapeo de Instituciones \\
\hline Aplacar la curva & $\begin{array}{l}\text { - Asamblea Legislativa. } \\
\text { - Caja Costarricense del Seguro Social (CCSS). } \\
\text { - Comisión Nacional de Emergencias (CNE). } \\
\text { - Consejo Nacional de Producción (CNP). } \\
\text { - Corporación Hortícola Nacional. } \\
\text { - Instituto Costarricense de Electricidad (ICE). } \\
\text { - Instituto Tecnológico de Costa Rica (TEC). } \\
\text { - Junta de Protección Social (JPS). } \\
\text { - Ministerio de Ambiente y Energía (MINAE). } \\
\text { - Ministerio de Educación Pública (MEP). } \\
\text { - Ministerio de Hacienda. } \\
\text { - Ministerio de Justicia y Paz. } \\
\text { - Ministerio de Obras Públicas y Transporte (MOPT). } \\
\text { - Ministerio de Planificación Nacional y Política Económica } \\
\text { (MIDEPLAN). } \\
\text { - Ministerio de la Presidencia. } \\
\text { - Ministerio de Salud (MS). } \\
\text { - Ministerio de Trabajo y Seguridad Social (MTSS). } \\
\text { - Correos de Costa Rica. } \\
\text { - Universidad de Costa Rica. }\end{array}$ \\
\hline Rescate social & $\begin{array}{l}\text { - Caja Costarricense del Seguro Social (CCSS). } \\
\text { - Consejo Nacional de la Persona con Discapacidad } \\
\text { (CONAPDIS). } \\
\text { - Instituto de Acueductos y Alcantarillados (AYA). } \\
\text { - Instituto Mixto de Ayuda Social (IMAS). } \\
\text { - Junta de Protección Social (JPS). } \\
\text { - Ministerio de Ambiente y Energía (MINAE). } \\
\text { - Ministerio de Educación Pública (MEP). } \\
\text { - Ministerio de Planificación Nacional y Política Económica } \\
\text { (MIDEPLAN). } \\
\text { - Ministerio de la Presidencia. } \\
\text { - Red de Cuido. } \\
\text { - Universidad de Costa Rica (UCR). }\end{array}$ \\
\hline $\begin{array}{l}\text { Readecuación } \\
\text { financiera }\end{array}$ & $\begin{array}{l}\text { - Banco Central de Costa Rica (BCCR). } \\
\text { - Banco Nacional de Costa Rica (BN). } \\
\text { - Caja Costarricense del Seguro Social (CCSS). } \\
\text { - Consejo Nacional de Supervisión del Sistema Financiero } \\
\text { (CONASSIF). } \\
\text { - Instituto Costarricense de Electricidad (ICE). } \\
\text { - Instituto de Desarrollo Rural (INDER). } \\
\text { - Instituto Nacional de Fomento Cooperativo (INFOCOOP). } \\
\text { - Instituto Nacional de Vivienda y Urbanismo (INVU). } \\
\text { - Instituto Costarricense de Pesca y Acuicultura (INCOPESCA). }\end{array}$ \\
\hline
\end{tabular}




\begin{tabular}{|c|c|}
\hline & $\begin{array}{l}\text { - Ministerio de Ambiente y Energía (MINAE). } \\
\text { - Ministerio de la Presidencia. } \\
\text { - Superintendencia General de Entidades Financieras (SUGEF). }\end{array}$ \\
\hline $\begin{array}{l}\text { Alivio financiero } \\
\text { y donaciones }\end{array}$ & $\begin{array}{l}\text { - Asamblea Legislativa. } \\
\text { - Caja Costarricense del Seguro Social (CCSS). } \\
\text { - Imprenta Nacional. } \\
\text { - Instituto Tecnológico de Costa Rica (TEC). } \\
\text { - Instituto Mixto de Ayuda Social (IMAS). } \\
\text { - Instituto Nacional de Aprendizaje (INA). } \\
\text { - Instituto Nacional de Seguros (INS). } \\
\text { - Junta de Protección Social (JPS). } \\
\text { - Ministerio de Economía, Industria y Comercio (MEIC). } \\
\text { - Ministerio de la Presidencia. } \\
\text { - Poder Judicial. } \\
\text { - Tribunal Supremo de Elecciones (TSE). } \\
\text { - Universidad de Costa Rica (UCR). } \\
\text { - Universidad Nacional a Distancia (UNED). }\end{array}$ \\
\hline $\begin{array}{l}\text { Apoyo } \\
\text { sectores }\end{array}$ & $\begin{array}{l}\text { - Asamblea Legislativa. } \\
\text { - Dirección General de Comercio Electrónico (DGCE). } \\
\text { - Instituto Costarricense de Turismo (ICT). } \\
\text { - Instituto Nacional de Fomento Cooperativo (INFOCOOP). } \\
\text { - Ministerio de Agricultura y Ganadería (MAG). } \\
\text { - Ministerio de Cultura y Juventud (MCJ). } \\
\text { - Ministerio de la Presidencia. }\end{array}$ \\
\hline
\end{tabular}

Elaboración propia a partir de datos del OPNAc (2020).

Si bien es cierto que el Poder Ejecutivo ha comandado las fuerzas de la institucionalidad costarricense, estas medidas no hubieran podido ser implementadas de una manera tan eficiente y coordinada si no fuera por la fortaleza del Estado social de derecho que existe en Costa Rica. Esta fortaleza institucional y el modelo de Estado social son condiciones por considerar al hablar de la gestión de los riesgos y las amenazas, pues han permitido la articulación especial de un conjunto de instituciones estatales; lo cual coincide en parte con la teoría en el punto de que las seguridades estatales impiden el crecimiento de los riesgos, pero distanciándose también, pues este modelo de Estado social surge en un país típicamente asociado al tercer mundo donde no debería de haber este tipo de fortalezas, por la carencia material que azota a este tipo de países.

La mayoría de la institucionalidad costarricense se reactivó para coordinar y reunir esfuerzos para luchar contra el COVID-19. Por ejemplo, en el caso de un poder de la República, como la Asamblea Legislativa, vemos que fue clave para asegurar el cumplimiento de la disminución de la curva, la recuperación económica y para brindar apoyo a la población. La Asamblea, a partir de la base del OPNA (2020), se evidencia que ha respaldado a la clase empre- 
sarial para evitar el colapso de las empresas, aprobó medidas como el cierre de establecimientos y la restricción vehicular, propuestas como la reducción de la jornada laboral en aquellas empresas que reportaron pérdidas y eliminó los pagos parciales sobre las utilidades, así como retrasó el pago del IVA a arrendamientos comerciales y aranceles por nacionalización.

Además, la Asamblea Legislativa aprobó una serie de créditos con organismos internacionales y traslados de superávits de otras instituciones, de tal manera que se pudiera asegurar que el Estado contara con mayor liquidez para enfrentar los gastos ocasionados por la gestión de la crisis sanitaria. Asimismo, como parte de la política social, la Asamblea ejecutó una serie de medidas para ayudar a la población como la aprobación del Bono Proteger o la habilitación de pensiones para adultos mayores en condición de pobreza. De esta manera, vemos que las acciones de la Asamblea Legislativa apoyaron los objetivos y metas de la estrategia gubernamental.

Por su parte, instituciones como el IMAS, la Red Cuido, AyA, Conapdis, entre otras, ejecutaron medidas para apoyar a la población más vulnerable en esta crisis sanitaria, que se pueden asociar a la política social. Por ejemplo, el AyA suspendió el corte de agua por morosidad, mientras el IMAS y la Red de Cuido anunciaron que sus servicios asistencialistas no se iban a ver afectados por la pandemia. Por su parte, la CCSS buscó adelantar el pago de las pensiones, y la Junta de Protección Social aseguró un subsidio de 200000 colones para cada vendedor afectado por la crisis; entre tanto, el IMAS se ha encargado de brindar atención especial para la persona adulta mayor y la población más vulnerable mediante el Bono Proteger. Y las universidades públicas fueron utilizadas para la producción de respiradores artificiales y mascarillas, o para ejecutar un plan interinstitucional entre la CCSS y el Instituto Clodomiro Picado enfocado en la creación de tratamientos para combatir el COVID-19 (OPNA 2020).

Con el caso costarricense, vemos cómo el Estado ha aprovechado el andamiaje institucional del Estado social de derecho para reorientar sus esfuerzos en pro de sumar fuerzas para combatir la pandemia y asegurar el cumplimiento de la estrategia de gestión de la crisis. En este sentido, es posible ver cómo diferentes instituciones, órganos y poderes de la República han sido utilizados para contener los riesgos de la pandemia, y solventar los problemas materiales que han surgido producto del cese de la actividad económica.

En síntesis, se observa cómo el Estado tiene un papel activo de protección en la gestión de los riesgos y las amenazas, así como su accionar es necesario para aliviar la tensión entre la salud pública y la economía, o la tensión entre la protección ante los riesgos médicos y la carencia material.

\section{Conclusiones}

El virus SARS-CoV-2 y la enfermedad del COVID-19 son, sin lugar a duda, unos de los riesgos imperceptibles y autoamenazantes que surgen del avance productivo y el conocimiento científico-técnico en la modernidad avanza- 
da. Parece ser que el deterioro ambiental, las actividades humanas que destruyen los ambientes naturales y el comercio de especies salvajes en condiciones inadecuadas favorecen el traspaso de patógenos peligrosos. La pandemia, al igual que los riesgos en la modernidad avanzada, creó verdaderos estados de excepción, donde el Estado tuvo que ejecutar medidas autoritarias e inéditas para contener los riesgos que emanaba el virus. Estas mismas medidas, en el caso costarricense, fueron las que ocasionaron serias consecuencias en otros ámbitos de la sociedad, generando una disminución en los ingresos de los hogares, una desaceleración económica y serias afectaciones a los mercados laborales.

La pandemia por COVID-19 permite ver cómo ha finalizado la transición de una sociedad industrial clásica a una sociedad industrial del riesgo y ejemplifica la importancia del rol del Estado en el crecimiento y prosperidad de los riesgos. Esto porque, en este contexto, el Estado fue el ente encargado de gestionar la paradoja del solapamiento de la carencia y los riesgos y debió enfrentar el efecto búmeran que generó sus medidas en otras áreas de la sociedad. Por ejemplo, tan pronto como los efectos de la pandemia se volvieron desastrosos, la gestión estatal fue clave para atender la recesión económica (Domínguez 2020, 45), mientras aún debía gestionar la crisis sanitaria. El papel del Estado es importante porque los Estados han demostrado ser el principal instrumento para controlar las crisis epidémicas, pues solo estos pueden implementar las cuarentenas y los esquemas de vacunación, así como el desarrollo del saneamiento para prevenir la propagación de enfermedades infecciosas (Domínguez 2020, 43).

A partir del caso costarricense, podemos ver cómo, a pesar de la carencia material y de un bajo nivel de desarrollo, existen en el sur global casos de regímenes de bienestar universales y unificados. De hecho, observamos que el Estado social fue clave para facilitar la coordinación y movilización de instituciones en el marco de la pandemia, demostrando cómo el Estado ha vuelto con fuerza y que su intervención resulta necesaria para tratar las crisis sanitarias y económicas que surgieron en el marco de la pandemia (Domínguez 2020, 46).

En general, el caso costarricense nos demuestra que si buscamos comprender el crecimiento y prosperidad de los riesgos, deberíamos observar el rol del Estado, que se halla mediado por el conjunto de medidas que forma una estrategia de gestión sanitaria, la influencia que tengan las élites en la implementación de dicha estrategia y las capacidades de los regímenes de bienestar o de la política social para hacer frente a los riesgos.

Estas variables son importantes para comprender el papel del Estado, ya que para controlar el crecimiento de los riesgos una estrategia de gestión debe tener éxito. Sin embargo, su éxito depende en buena parte de la interrelación entre estos tres factores, lo que queda claro en el caso costarricense, donde los riesgos del virus crecieron por la influencia de las élites, dado que dicha influencia contribuyó a la flexibilización de la estrategia de gestión sanitaria, la cual fue la que terminó concediendo un alza en el riesgo de contagio y 
muerte por el virus. El caso costarricense es importante porque nos demuestra que, contrario a lo que apunta la teoría, la carencia material y el nivel de desarrollo no son determinantes para comprender el crecimiento de los riesgos en la modernidad avanzada. Aun a pesar de que los riesgos afectan de manera desigual a las clases, géneros, razas y países (Domínguez 2020, 4243), claramente que no resulta correcto afirmar que los riesgos crecen mejor en países del tercer mundo que en países del primer mundo. Tampoco se puede afirmar, a la luz del caso analizado, que los países del sur global tienen menores capacidades para enfrentar los riesgos en la modernidad avanzada.

Así pues, en síntesis, abordar el rol del Estado permite refutar la teoría y postular que el uso de categorías como el primer y tercer mundo es errónea y están cargadas de una visión jerarquizante y eurocéntrica. En este sentido, al hablar de que en el tercer mundo, por la miseria material y el subdesarrollo en el que se ve sumido, lo hace terreno cultural y político para que crezcan los riesgos, no solo es erróneo, sino que también refleja una preconcepción negativa y peyorativa sobre los países del sur global. En realidad, si queremos comprender mejor el crecimiento de riesgos y ejecutar mejores estrategias de contención de crisis inesperadas, debemos necesariamente recurrir a observar puntualmente el conjunto de medidas que conforman una estrategia de gestión sanitaria, los arreglos y capacidades de la política social y la influencia de las élites en el rol que adopta el Estado, ante crisis coyunturales críticas como la actual.

\section{Bibliografía}

Agamben, Giorgio. 2020. "La invención de una epidemia». En Sopa de Wuhan, editado por Pablo Amadeo, 17-19. Buenos Aires: Aislamiento Social Preventivo y Obligatorio. Acceso el 22 de agosto del 2020: http://iips.usac.edu.gt/wp-content/uploads/2020/03/Sopa-de-WuhanASPO.pdf

Amarís, Orlando. 2020. «COVID-19: Expresión del impacto global del capitalismo en la biodiversidad». Revista Rupturas 10: 33-37. DOI: https://doi.org/10.22458/rr.v10i0

Antía, Florencia. 2018. «Regímenes de política social en América Latina: una revisión crítica de la literatura». Desafíos, 30(2), 193-235. DOI: http://dx.doi.org/10.12804/revistas.urosario.edu.co/desafios/a.4802

Bachelard, Gaston. 1973. Epistemología. Barcelona: Anagrama.

Badiou, Alain. 2020. "Sobre la situación epidémica». En Sopa de Wuhan, editado por Pablo Amadeo, 67-78. Buenos Aires: Aislamiento Social Preventivo y Obligatorio. Acceso el 22 de agosto del 2020: http://iips.usac.edu.gt/wp-content/uploads/2020/03/Sopa-de-WuhanASPO.pdf 
Banco Central de Costa Rica (BCCR). 2021. Informe de Política Monetaria. Costa Rica: BCCR. Acceso el 10 de agosto del 2021: https://www.bccr.fi.cr/publicaciones/DocPolticaMonetarialnflacin/Docum ento-IPM-Abril-2021.pdf

Banco Central de Costa Rica (BCCRa). 2020. Informe de Política Monetaria. Costa Rica: BCCR. Acceso el 11 de noviembre del 2020: https://www.bccr.fi.cr/publicaciones/DocPolticaMonetarialnflacin/IPM_oc tubre_2020.pdf

Banco Central de Costa Rica (BCCRb). 2020. Revisión del Programa Macroeconómico 2020-2021. Costa Rica: BCCR. Acceso el 11 de noviembre 2020: https://www.bccr.fi.cr/publicaciones/DocPolticaMonetarialnflacin/Revsio n-Programa_Macroeconomico-2020-2021_informe.pdf

Banco Interamericano de Desarrollo. 2011. Pautas para la Elaboración de Estudios de Caso. Banco Interamericano de Desarrollo. Washington: BID. Acceso el 29 de diciembre del 2020: https://publications.iadb.org/publications/spanish/document/Pautaspara-la-elaboraci\%C3\%B3n-de-estudios-de-caso.pdf

Barahona, Manuel, Allen Cordero y Priscilla Sibaja. 2020. Protesta y Movilización Social en Tiempos de Pandemia: Algunas Tendencias, Características y Preguntas. Costa Rica: FLACSO.

Beck, Uldrich. 1998. «Sobre el volcán civilizatorio: los contornos de la sociedad del riesgo». En La sociedad del riesgo: hacia una nueva modernidad, editado por Ulrich Beck, 25-94. Barcelona: Paidós.

Bello, Alejandra. 2015. «Análisis de la categoría Tercer mundo como dispositivo moderno/colonial de reproducción de hegemonía euroreferenciada». Universitas Humanística 79: 41-62. DOI: http://dx.doi.org/10.11144/Javeriana.UH79.actm

Benavides, Julio, Ángel Ruiz-Mantecón, M. Victoria Moreno-Arribas, Lara Lloret, Montserrat Vilà. 2020. "Una visión global de la pandemia COVID-19: Que sabemos y que estamos investigando desde el CSIC». En Una visión global de la pandemia COVID-19: qué sabemos y qué estamos investigando desde el CSIC. Editado por Consejo Superior de Investigaciones Científicas, 15-22. España: CSIC. DOI: http://dx.doi.org/ 10.20350/digitalCSIC/12596

Cárdenas, Julián, Diego Martínez y Francisco Robles. 2020. Élites empresariales y desigualdad en tiempos de pandemia en América Latina. 29 (3).

Coto, Paulo. 2020. «En vez de escribir el Rey Lear en el tiempo del coronavirus». Revista Rupturas 10: 3-6. DOI: https://doi.org/10.22458/rr.v10i0 
Domínguez, José. 2020. «Coronavirus, riesgo y cambio social». En Alerta Global. Políticas, movimientos sociales y futuros en disputa en tiempos de pandemia, editado por Breno Bringel y Geoffrey Pleyers, 41-52. Lima: CLACSO. Acceso el 28 de septiembre del 2021: http://biblioteca.clacso.edu.ar/clacso/se/20200826014541/Alertaglobal.pdf

Durán, Giovanny. 2018. «El «desarrollo»: debate sobre su concepción desde la antropología en los países del tercer mundo». Revista Euroamericana de Antropología 5, 103-109. DOI: http://dx.doi.org/10.14201/rea20185103109

Esping Andersen, Gosta. 1990. Los Tres Mundos del Estado de Bienestar. Valencia: Institució Alfons el Magnanim.

Filgueira, Fernando. 1998. Entre pared y espada: ciudadanía social en América Latina.

Franco, Rolando. 1982. Las grandes controversias de la política social. Santiago: CEPAL.

Han, Byung-Chul. 2020. «La emergencia viral y el mundo de mañana». En Sopa de Wuhan, editado por Pablo Amadeo, 97-112. Buenos Aires: Aislamiento Social Preventivo y Obligatorio. Acceso el 22 de agosto del 2020: $\quad$ http://iips.usac.edu.gt/wp-content/uploads/2020/03/Sopa-deWuhan-ASPO.pdf

Harvey, David. 2020. «Política anticapitalista en tiempos de coronavirus». En Sopa de Wuhan, editado por Pablo Amadeo, 79-96. Buenos Aires: Aislamiento Social Preventivo y Obligatorio. Acceso el 22 de agosto del 2020: $\quad$ http://iips.usac.edu.gt/wp-content/uploads/2020/03/Sopa-deWuhan-ASPO.pdf

Hasell, Joe, Esteban Ortiz-Ospina, Hannah Ritchie y Max Roser. 2020. «Pandemia de coronavirus (COVID-19)». Acceso el 1 de enero de 2020: https://ourworldindata.org/coronavirus

Horowitz, Irving. 1972. La sociedad industrial contemporánea. Traducido por Margarita Prieto y Julieta Campos. Madrid: Siglo Veintiuno.

Instituto Nacional de Estadística y Censos (INECa). 2020. Encuesta Continua de Empleo al tercer trimestre del 2020. Resultados Generales. Costa Rica: INEC. Acceso el 25 de agosto del 2020: https://www.inec.cr/sites/ default/files/documetos-biblioteca-virtual/reeceiiit2020.pdf

Instituto Nacional de Estadística y Censos (INECb). 2020. Encuesta Nacional de Hogares Julio 2020 Resultados Preliminares. Costa Rica: INEC. Acceso el 27 de octubre del 2020: https://www.inec.cr/sites/default/files/ documetos-biblioteca-virtual/renaho2020.pdf

Martínez, Juliana y Sánchez-Ancochea, Diego. 2019. La búsqueda de una política social universal en el Sur: actores, ideas y arquitecturas. Costa Rica: Editorial UCR. 
Minteguiaga, Analía y Gemma Usabart-González. 2017. «Esping-Andersen en América Latina El estudio de los regímenes de bienestar». Política y Gobierno 24 (1): 213-236.

Nancy, Jean Luc. 2020. «Excepción viral». En Sopa de Wuhan, editado por Pablo Amadeo, 29-30. Buenos Aires: Aislamiento Social Preventivo y Obligatorio. Acceso el 22 de agosto del 2020: http://iips.usac.edu.gt/wpcontent/uploads/2020/03/Sopa-de-Wuhan-ASPO.pdf

Observatorio de la Política Nacional (OPNAa). 2020. Análisis de coyuntura política nacional. La Costa Rica política en tiempos del FMl. Costa Rica: Universidad de Costa Rica. Acceso el 17 de febrero del 2021: https://opna.ucr.ac.cr/images/AdC2020/OPNA_AnalisisideCoyuntura_32020 agosto - setiembre _FINAL.pdf

Observatorio de la Política Nacional (OPNAb). 2020. «Análisis de coyuntura política nacional: La Costa Rica política en tiempos del FMI II». Costa Rica: Universidad de Costa Rica. Acceso el 17 de febrero del 2021: https://opna.ucr.ac.cr/images/AdC2020/Analisis_de_coyuntura_4 __2020_oct_-_nov.pdf

Observatorio de la Política Nacional (OPNAc). 2020. «Medidas gubernamentales para aliviar la situación COVID-19». Costa Rica: Universidad de Costa Rica. Acceso el 26 de octubre del 2020: https://docs.google.com/spreadsheets/d/1icBDBr7PM891eCaqB3zen22 8XQSlqRfza4GfFbRhgl4/edit?usp=drivesdk

Organización Mundial de la Salud (OMS). 2020. «Preguntas y respuestas sobre la enfermedad por coronavirus (COVID-19)». Acceso el 29 de diciembre del 2020. https://www.who.int/es/emergencies/diseases/novel-coronavirus-2019/ advice-for-public/q-a-coronaviruses\#: :text=\%C2\%BFQu \%C3\%A9\%20es\%20la\%20COVID\%E2\%80\%9119,China) $\% 20$ en \%20diciembre\%20de\%202019.

Pineda, Andrey. 2020. «COVID-19: Encrucijadas y respuestas humanas». Revista Rupturas 10: 13-16. DOI: https://doi.org/10.22458/rr.v10i0

Quijano, Aníbal. 2014. «Colonialidad del poder, eurocentrismo y América Latina». En Cuestiones y horizontes: de la dependencia históricoestructural a la colonialidad/descolonialidad del poder, editado por CLACSO, 978-987. Buenos Aires: CLACSO. Acceso el 27 de mayo del 2021: http://biblioteca.clacso.edu.ar/clacso/se/20140507042402/eje38.pdf

Reyna, Víctor. 2018. «Ulrich Beck y el malestar del trabajo». Revista Sociológica 33 (95): 93-124. Acceso el 11 de agosto del 2020: http://www.scielo.org.mx/pdf/soc/v33n95/2007-8358-soc-33-95-93.pdf

Sales, Tomeu. 2009. «Modernidad, política y globalización. La teoría social y política de Ulrich Beck». Tesis doctoral. Universitat de les Illes Balears. 
Vargas, Luis. 2020. «Covid-19, marginalidad y pobreza: El desafío fundamental». Revista Rupturas 10: 115-116. DOI: https://doi.org/10.22458/rr.v10i0

Venneson, Pascal. 2013. «Estudios de caso y seguimiento de procesos: teorías y prácticas». En Enfoques y metodologías de las Ciencias sociales: una perspectiva pluralista, editado por Donatella Della Porta y Michael Keating. España: Akal.

Wallace, Arturo. 2020. «Cómo fueron controladas las epidemias de SARS y MERS, otros coronavirus para los que no hay vacuna». Reino Unido: BBC. Acceso el 1 de enero del 2020: https://www.bbc.com/mundo/noticias-52797076. 